\title{
Goodwin Reel İş Çevrimi Temel Alınarak Adalet ve Kalkınma Partisi Dönemine Politik İktisadi Bir Bakış
}

A Political Economic Perspective to the Justice and Development Party's Period Taking into Account Goodwin Business Cycle Model

Cem Mehmet BAYDUR ${ }^{1}$

Geliş tarihi: 31.10.2016, Kabul tarihi: 29.01.2017, Basım tarihi: 10.06.2017

\section{Özet}

Richard Goodwin, Marx’ın ücret ve kar çelişkisini diferansiyel denkleme döken ve dinamik şekilde inceleyen bir birikim modeli geliştirmiştir. Marx’ın konjonktür analizinin tam aksine Goodwin analizi, kar oranlarının konjonktür boyunca dalgalansa bile genelde sabit olduğu sonucuna ulaşmıştır. Model aynı zamanda konjonktür süresini başta sermaye hasıla katsayısı olmak üzere birkaç parametreye dayanarak hesaplayabilmektedir. Makalenin amacı da, Goodwin modelinden faydalanarak Türkiye ekonomisinin konjonktür süresini farklı sermaye hasıla katsayıları için hesaplanmaktır. Makalede farklı sermaye stoku tanım ve hesaplamalarına göre Türkiye ekonomisi için 20 ve 39,2 yıl olmak üzere iki farklı konjonktür süresi hesaplanmıştır. Bu hesaplamalara dayanarak Adalet ve Kalkınma Parti'sinin (AKP) seçim sonuçları hesaplanan konjonktüre göre yorumlanmıştır.

Anahtar Kelimeler: Goodwin Modeli, Konjonktür, Bölüşüm, Seçim, AK Parti İktidar Dönemi

JEL Kodlar1: P16, P47

\begin{abstract}
Richard Goodwin have analized Marx's wage and profits conflict with the aid of two differential equations. It has developed a model of accumulation. Marx's in the model reduced profit margins over business cycle. The profit rate in Goodwin model fluctuates according to conjuncture and it is constant. Model can be calculated time of conjuncture based on capital output ratio. The purpose of Article with help of Goodwin models calculate to time of conjuncture time of the Turkish economy. These calculations was made for different capital output coefficients. For two different capital stock in Turkey has to two different conjuncture time. It is one of them 20 years, the other is 39,2 years. According to conjuncture account have been interpreted election results of the AKP (Justice and Development Party).
\end{abstract}

Keywords: Goodwin Model, Conjuncture, Distribution, Politics, AK Party, The Government Period

JEL Codes: P16, P47

\footnotetext{
${ }^{1}$ Muğla Sttkı Koçman Üniversitesi, İktisadi ve İdari Bilimler Fakültesi, İktisat Bölümü, Prof. Dr.

cbaydur@mu.edu.tr
} 


\section{Giriş}

Kar ve ücret arasındaki çelişkili/çekişmeli ilişki ve kapitalist sistemin birikime dayanan dinamiği her iktisat doktrinde bölüşümü merkezi teorik konulardan biri haline getirmektedir. Birikim dinamiği iş çevrimleri/krizler ile beraber işlediğinden sürekli bir politik ilgiyi de üzerinde tutmaktadır. Kısacası birikim ve konjonktür merkezi bir ekonomik politik meseledir. Bu noktada Marx'ın birikim, konjonktür ve kriz analizi açısından iktisat teorisinde önemli bir yeri bulunmaktadır. Marx’ın konjonktüre bakışı, artan mutlak ve nisbi sömürüye rağmen kar oranlarının zamanla düşmesi, ekonomideki krizlerin giderek büyümesi ve şıklaşması şeklinde özetlenebilir. Klasik bir iktisatçı olarak Marx karamsar bir konjonktür görüşüne sahiptir. Marx’ın teorisinin dayandı̆̆ı emek değer teorisi ve getirdiği artık değer kavramlarının gözlenebilir olmadığını dikkate alarak, bunun yerine, ücret ve kar ilişkisini Marx’ın temel varsayımlarını kullanarak formüle eden Richard Goodwin ilginç bir model geliştirmiştir. Goodwin modeli Lotka-Volterra'nın av ve avc1 modeline dayanmaktadır. Birbirinden bağımsız bir şekilde Amerikalı biyolist Alfred Lotka ve İtalyan matematikçi Vito Volterra Adriyatik denizindeki balık popülasyonuna ilişkin dinamik bir av ve avc1 modeli geliştirmişlerdir. Goodwin belli bir bölgede yaşayan av hayvanları ile avcılar arasındaki popülasyon ilişkisini Marx'ın birikim ve konjonktür analizine adapte ederek işçilerle kapitalistler arasındaki bölüşüm mücadelesini incelemiştir. Bilindiği üzere avc1 hayvanlar ve avları karşılıklı olarak birbirilerini kontrol eder. Av hayvanı say1s1 artarsa avc1 say1s1 da artar. Avcı sayısındaki artış bir süre sonra av hayvanı sayısının azalmasına dolayısıyla avcı sayısının da azalmasına neden olur. Bu döngü devam edip gider. Goodwin modelinde kapitalistler ve işçiler, av ve avc1 yerine konularak birikim süreci dinamik olarak sorgulanmaktadır. Goodwin modeli ilginç denge özelliklerine sahiptir. Model "...isgü̈üne katılımlar soğurmaya yetecek büyüklükte sabit bir büyüme hrz ve istibdam sürdürebilecek sabit bir kar oranna sabiptir... Goodwin temel olarak artık değer ve benzeri gereçleri kullanmadan Marx'in devrevi dalgalanmasin matematiksel olarak formüle edilebileceğini göstermistir. Ücretler ve karlar ulusal gelirin iki payıdır; emek ve sermaye bunun üzerinde mücadele eden iki talep sahibidir. Ne var ki, bunlarn mücadelesi karşılıklıdır aym zamanda karşılıklı bağımlihklarm kabul eder. Goodwin'in önerdiği matematiksel formülasyon sabit uzunlukta ve sabit büyüklïkte devrevi dalgalanmalar üretir" (Desai, 2011: 106-107).

Bu makalenin temel teorik amac1 Goodwin konjonktür süresinin nasıl hesaplandığını göstermektedir. Konjonktürün canlanma ve daralma açısından sürelerinin hesaplanması politika ve iktisat açısından kısacası politik iktisat açısından önemlidir. Çoğu zaman ekonominin (toplumun) nereye gittiğini anlamak isteyen iktisatçılar miyopik bir bakış açısı ile sadece birkaç yılın büyüme, yatırım verilerine bakarak siyasal değerlendirmeler yaparlar. Kapitalistlerin gelirden aldığı pay veya yatırımların gelir içindeki 
payları ile ilgili birkaç yıllık verilerin gelişimine bakarak siyasal çıkarımlar yapmak yanıltıcı olabilir. Konjonktür süresinin tamamını dikkate alarak siyasal çıkarımlar yapmak daha sağlık bir yoldur. Özelde de Türkiye'de on dört yildır iktidarda olan Adalet ve Kalkınma Partisi'nin elde ettiği seçim başarılarını analiz ederken birkaç yıllık ve birkaç makro ekonomik veri yerine, bu verileri ekonomik konjonktürün tamamina bakarak değerlendirmek gerekmektedir. Türkiye ekonomisinde sermaye birikimi açısından kapitalistlerin gelirden aldığı payın ne kadarlık bir konjonktür süresine sahip olduğunu hesaplamak gerekmektedir. Makalenin temel amac1 da Goodwin konjonktürünün süresini Türkiye ekonomisi için hesaplamak ve sermaye biçim/büyüklügü ile ekonomik konjonktür süresi arasındaki ilişkiyi göstermek, bu bağlamda bazı siyasal ve ekonomik değerlendirmeler yapmaktir.

\section{Goodwin Modelinin Varsayımları ve Goodwin Konjonktürünün (Dalgasının) Süresinin (Periyodunun) Hesaplanması}

Marx’a göre değer ve karın kaynağı canlı emektir. Gerek mutlak gerekse nisbi sömürü karın ve birikimin kaynağıdır. Nisbi sömürüdeki gelişme üretimden canlı emeği kovduğu için kar oranlarının düşmesi ve krizlerin giderek büyümesi kaçınılmazdır (Marx, 2012a: 215-218; 390-391 ve 604605). Richard Goodwin Marx'ın iki sınıfının davranışlanını birer diferansiyel denkleme (modele) dönüştürmek suretiyle dinamik bir çözümleme yaparak Marx'tan faklı sonuçlar elde eder (Desai, 2011: 106-107). Goodwin'e göre kar oranlarnm sürekli düsmesi mümkün değildir ve is çevrimine (konjontüre) tabidir. Kar oran konjonktüre göre yukar ve aşă̆yya doğru dalgalansa bile konjontürün genelinde sabittir. Dolayısıyla model Marx'ın krizlerin giderek daha sık ve büyük dalgalanmalar seklinde ortaya çıacak önermesini kabul etmez. Şimdi modelin bu sonuçlarını görmek için gerekli varsayımları yazarak modeli tanıtalım. Modelimiz (Harvie, 2000: 349-376), (Weber, 2005: 1-28), (Desai ve diğerleri, 2003: 1-14) çalışmalarına ve aşağıdaki temel varsayımlara dayanmaktadır:

1- Teknik gelişme veri veya dişsaldır.

2- İsgücünün büyüme hızı veridir.

3- İki üretim faktörü vardır: Sermaye ve emek.

4- Bütün değişkenler reeldir.

5- Ücretlerin tamamı tüketilir, karın tamamı da yatırıma gider.

6- Sermaye ç1ktı oranı sabittir.

7- Ekonomi tam istihdama yaklaştıkça reel ücretler artar.

Modeldeki değişkenlerle ilgili kısaltmalar şunlardır: (a) işçi başına çıkt1 miktarını göstermektedir. İşçi başına çıktı $(\propto)$ oranında artmaktadır. $(\propto)$ işgücü verimliliğindeki artış hızıdır. (n) emek gücünü göstermekte, nüfus $\operatorname{artışı~da~}(\beta)$ oranında artmaktadır. $(\sigma)$ sermaye çıktı (hasıla) oranını, (q) reel çıktı (hasıla) miktarını, (k) sermaye stokunu, (I) istihdam düzeyini, (w) reel 
ücreti, (v) istihdam oranını ve (u) da işçilerin milli gelirden aldığ1 pay1 göstermektedir. Özetlenirse, $\sigma=k / q, \quad l=q / a, u=l w / q=w / a, v=$ $l / n$.

Kapitalist ve işçilerin davranışlarını basit birer denklemle tanımlanabilir. Kapitalistler bütün karlarını tasarruf ederek birikim için yeniden yatırmaktadırlar. Bakınız (1) nolu denklem.

$$
\dot{k}=(1-u) q
$$

İşçilerde ücretlerinin tamamını harcamaktadır. Ücretlerde Phillips eğrisindeki gibi belirlenmektedir. İstihdam düzeyi ile ücretler arasında pozitif yönlü bir ilişki vardır. Bakınız (2) nolu denklem.

$$
\frac{\dot{w}}{w}=-\gamma+\rho v
$$

İşçilerin gelirden aldığı pay $u=\frac{l w}{q}$ olduğuna göre (1) nolu denklem, (3) nolu denklemde yerine konularak yeniden yazılabilir. (3) nolu denkleme göre kapitalistlerin birikim hızıyla (kar oranı) işçilerin gelirden aldığı pay arasında ters yönlü bir ilişki bulunmaktadır.

$$
\dot{k}=\left(1-\frac{w}{a}\right) q
$$

Sermaye çıtı oranının optimum değeri sorgulanarak, karlılık oranı ile çıktı büyüme oranının birbirine eşit olduğu gösterilebilir. Bakınız (4) nolu denklem.

$$
\begin{aligned}
& \frac{d(k / q)}{d t}=0, \frac{d(k / q)}{d t}=\frac{\left(\frac{d k}{d t}\right) q-\frac{d q}{d t} k}{q^{2}}=0, \frac{\left(\frac{d k}{d t}\right) q}{q^{2}}=\frac{\frac{d q}{d t} k}{q^{2}} \\
& \frac{d q}{d t}=\dot{q} \text { ve } \frac{d k}{d t}=\dot{k} \quad \text { olarak kisaltılırsa } \frac{\dot{k} q}{q^{2}}=\frac{\dot{q} k}{q^{2}}, \frac{\dot{k}}{k}=\frac{\dot{q} q^{2}}{q q^{2}}, \frac{\dot{k}}{k}=\frac{\dot{q}}{q}
\end{aligned}
$$

(3) nolu denklemin her iki tarafı " $k$ " ya bölünür ve (3) nolu denklemden faydalanılarak birikim dinamiklerini veren bir denklem (5) elde edilebilir.

$$
\frac{\dot{k}}{k}=\frac{\dot{q}}{q}=\frac{\left(1-\frac{w}{a}\right)}{\sigma}
$$

İşücü verimliliği $a=q / l$ dinamik olarak aşağıdaki (7) nolu denklemdeki gibi yazılabilir.

$$
\begin{aligned}
& \frac{\dot{a}}{a}=\frac{\dot{q}}{q}-\frac{\dot{l}}{l} \\
& \frac{\dot{a}}{a}=\propto \text { olduğuna göre }
\end{aligned}
$$




$$
\propto=\frac{\dot{q}}{q}-\frac{i}{l} \quad \rightarrow \frac{i}{l}=\frac{\dot{q}}{q}-\alpha=\frac{\left(1-\frac{w}{a}\right)}{\sigma}-\propto=\frac{(1-u)}{\sigma}-\propto
$$

Emek arzı da $\frac{\dot{n}}{n}=\beta$ oranında artmakta ve istihdam düzeyinin de $v=$ $l / n$ ilişkisine göre belirlenmektedir. Bu tanımlanan oranlar işgücünün istihdam dinamiklerini veren türevsel denklemlere dönüştürülebilir ve aşağıdaki gibi yazılabilir.

$$
\begin{aligned}
& \frac{\dot{v}}{v}=\frac{i}{l}-\frac{\dot{n}}{n}=\frac{(1-u)}{\sigma}-\propto-\beta, \quad \frac{\dot{v}}{v}=\frac{(1-u)}{\sigma}-(\alpha+\beta), \\
& \dot{v}=\left[\frac{(1-u)}{\sigma}-(\alpha+\beta)\right] v
\end{aligned}
$$

(8) nolu denklem Goodwin modelinin ilk dinamik denklemidir. Diğer dinamik denklem de işgücünün gelirden aldığı payı tanımlayan denklemdir. Diğer denklem $u=w / a$ tanımı dinamize edilerek (9) nolu denklemdeki gibi yazilabilir:

$$
\frac{\dot{u}}{u}=\frac{\dot{w}}{w}-\frac{\dot{a}}{a}=-\gamma+\rho v-\propto, \quad \dot{u}=[-(\gamma+\propto)+\rho v] u
$$

(8) ve (9) nolu denklemler Lotka-Volterra'nin av/avc1 denklemidir. (9) nolu denklem avc1 denklemidir. (u) ya avc1, (v) ye de bir süreliğine av olarak bakılarak iki denklem şu şekilde açılanabilir. (9) nolu denklemdeki $-(\gamma+\propto)$ terimi av olmadığı durumda avcının yok olma hızıdır. $(\rho v)$ terimi de avcının av olması durumunda hangi hızda artacağını göstermektedir. (8) nolu denklemdeki $\frac{(1-u)}{\sigma}$ terimi de avcı durumuna göre avın gelişimini belirlemektedir. Diğer terimlerde avc1 olmadığ1 durumda av nüfusunun gelişimini göstermektedir. Bu denklemler yardımıyla av ve avcı nüfusunu verecek çözümler veya bu değisskenlerin zaman patikası yazılabilir. Başlangı̣ koşulları $\left(v_{0}, u_{0}\right)$ verilmek kaydıyla (u)'nun ve (v)'nin zaman patikası: $v=$ $f(u, t)$ ve $u=f(v, t)$. Bu av ve avc1 arasındaki ilişki basit bir döngüye neden olur. Şekil 1'de de bu döngü tasvir edilmektedir: 


\section{Şekil 1: Av ve Avcı İlişkisi}

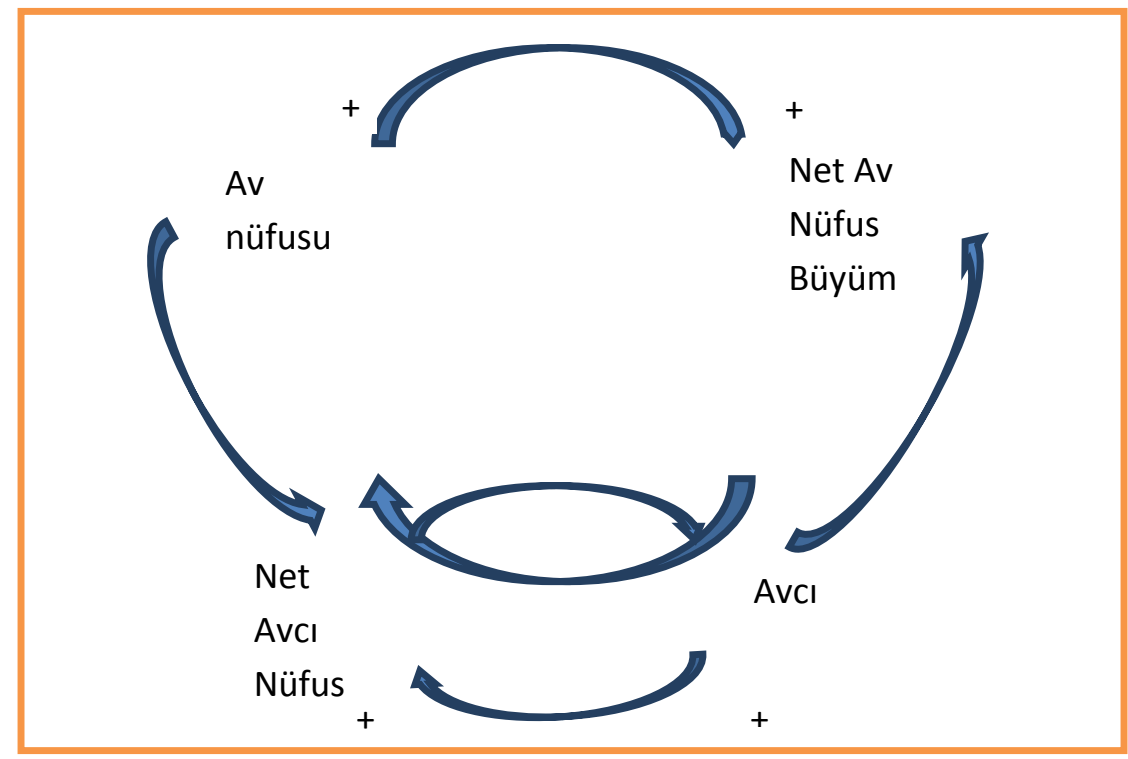

Kaynak: Weber, 2005: 1-28.

(8) ve (9) nolu denklemlerin çözümleme süreci iki aşamada yapılabilir. Birinci aşamada uzun dönem denge değerleri araştırllır. İkinci aşamada denklemlerin kökleri yardımıyla sistem istikrar ve istikrarsızlı̆g dinamik açısından sorgulanabilir.

Uzun dönem işgücünün ve istihdam düzeyinin denge değerleri varsa $u *$ $=k$ ve $v *=z$ varsayımlarından faydalanarak hesaplanabilir. (8) ve (9) nolu denklemdeki bu değişkenlerin değişimini ifade eden türevleri uzun dönem çözümlemesi için $\dot{u}=0$ ve $\dot{v}=0$ olmalıdır. Buna göre çözümleme yapilirsa.

$$
\begin{aligned}
& 0=-(\gamma+\propto)+\rho v ; \quad v^{*}=\frac{\gamma+\propto}{\rho} \\
& 0=\left[\frac{(1-u)}{\sigma}-(\propto+\beta)\right] ; \quad u^{*}=1-(\propto+\beta) \sigma
\end{aligned}
$$

(11) nolu denkleme göre işgücünün milli gelirden aldığ1 payın pozitif olabilmesi için $(\alpha+\beta) \sigma<1$ veya $\frac{1}{\sigma}>(\alpha+\beta)$ koşulunun çözümleme için konulması gerekir. Emek verimliliği ile emek arzı artışının toplamının sermaye verimliliğinde küçük olması gerekir.

(8) ve (9) nolu denklem sisteminin köklerini bularak dinamik açıdan değerlendirme yapılabilir. Gerek ücretlerin gelirden aldığı payın gerekse istihdam düzeyindeki değişmelerin nasıl değiştiğini bulabilmek için her iki 
büyüklügün de uzun dönem denge değerlerinden cari değerlerinin saptığını varsaymak gerekir. Buna göre $U=u-u *$ ve $V=v-v *$. (9) nolu denklem aşağıdaki gibi yeniden yazılabilir:

$$
\begin{aligned}
& \dot{u}=-(\propto+\beta) \frac{\rho}{\rho} u+\rho v u \text { ve } v^{*}=\frac{\gamma+\propto}{\rho} \text { olduğundan } \\
& \dot{u}=-\rho v^{*} u+\rho v u, \quad \dot{u}=\rho\left(v^{*}-v\right) u \quad \text { veya } \dot{u}=\rho(V) u \\
& u=U+u^{*} \text { olduğundan } \\
& \dot{u}=\rho(V)\left(U+u^{*}\right) \\
& u^{*}=1-(\propto+\beta) \sigma \quad \text { ve } \dot{U}=\dot{u} \text { olduğundan } \\
& \dot{U}=\dot{u}=\rho V(U+[1-(\propto+\beta) \sigma])=F^{1}(U, V)
\end{aligned}
$$

Benzer bir dönüşüm (8) nolu denklem için yapılabilir.

$$
\begin{aligned}
\dot{v} & =\frac{(1-u)}{\sigma} v-(\alpha+\beta) \frac{\sigma}{\sigma} v \quad \text { veya } \quad \dot{v}=\frac{1}{\sigma}(v-u v-(\alpha+\beta) \sigma v) \\
\dot{v} & =\frac{1}{\sigma}([1-(\alpha+\beta) \sigma] v-u v) \\
u^{*} & =1-(\alpha+\beta) \sigma \quad \text { olduğundan, } \\
\dot{v} & =\frac{1}{\sigma}\left(u^{*} v-u v\right) \quad \text { veya } \quad \dot{v}=\frac{1}{\sigma}\left(u^{*}-u\right) v=-\frac{1}{\sigma}\left(u-u^{*}\right) v= \\
-\frac{1}{\sigma} U v & =-\frac{1}{\sigma} U\left(V+v^{*}\right) \\
v^{*} & =\frac{\gamma+\alpha}{\rho} \text { olduğundan, } \\
\dot{v} & ==-\frac{1}{\sigma} U\left(V+\frac{\gamma+\alpha}{\rho}\right)=F^{2}(U, V)
\end{aligned}
$$

(12) ve (13) nolu denklemlerin doğrusallaştırılmış formül yardımıyla her bir denge noktasının lokal stabilite özelliklerini belirlemek için Jocabian matrisini dikkate almak gerekir. Bunun için $\mathrm{u}=\mathrm{u}^{*} \mathrm{ve} \mathrm{v}=\mathrm{v}^{*}$ noktalarında (12) ve (13) nolu denklemlerin doğrusallaştırılmış hali aşağıdaki matris formunda yazılabilir:

$$
\begin{gathered}
\left(\begin{array}{l}
\dot{u} \\
\dot{v}
\end{array}\right)=\left[\begin{array}{ll}
F_{U}^{1} & F_{V}^{1} \\
F_{U}^{2} & F_{V}^{2}
\end{array}\right]\left(\begin{array}{l}
U \\
V
\end{array}\right) \\
J=\left[\begin{array}{ll}
F_{U}^{1} & F_{V}^{1} \\
F_{U}^{2} & F_{V}^{2}
\end{array}\right]=\left[\begin{array}{cc}
\rho V & \rho[1-(\propto+\beta) \sigma] \\
-\frac{\gamma+\alpha}{\sigma \rho} & -\frac{1}{\sigma} U
\end{array}\right] \text { ve } U=u-u *=0, V= \\
v-v *=0 \text { ise }
\end{gathered}
$$




$$
J=\left[\begin{array}{cc}
0 & \rho[1-(\alpha+\beta) \sigma] \\
-\frac{\gamma+\alpha}{\sigma \rho} & 0
\end{array}\right]
$$

Jocabian determinantı kullanılarak da Goodwin modelinin karakteristik kökleri elde edilebilir.

$$
\begin{aligned}
& |J-r I|=\left|\begin{array}{cc}
-r & \rho[1-(\alpha+\beta) \sigma] \\
-\frac{\gamma+\alpha}{\sigma \rho} & -r
\end{array}\right|=0(15), \\
& r^{2}+\left(\frac{\gamma+\alpha}{\sigma \rho}\right)(\rho[1-(\propto+\beta) \sigma])=0
\end{aligned}
$$

(16) nolu denklem ikinci dereceden bir denklemdir. $\left(\frac{\gamma+\alpha}{\sigma \rho}\right)(\rho[1-$ $(\alpha+\beta) \sigma])$ ifadesi pozitif ve kare kökün içerisinin negatif olduğu için iki sanal kökü bulunmaktadır.

$$
\begin{aligned}
& r_{1,2}=\sqrt{-\left\{\left(\frac{\gamma+\alpha}{\sigma \rho}\right)(\rho[1-(\alpha+\beta) \sigma])\right\}} \quad \text { ve } \quad \sqrt{-1}=i, \quad r_{1,2}= \\
& \sqrt{\left\{\left(\frac{\gamma+\alpha}{\sigma \rho}\right)(\rho[1-(\propto+\beta) \sigma])\right\}} i
\end{aligned}
$$

(17) nolu denklemdeki kökleri kullanarak (uv) uzayında $\left(\mathrm{u}^{*}, \mathrm{v}^{*}\right)$ merkezli kapalı sonsuz tane döngü (konjonktür) (başlangıç koşullarına bağlı olarak) çözümü yazılabilir. Bu çalışmada Goodwin döngülerinin (cycles) süresi hesaplanmak istendiğinde köklerin radyan cinsinden eşitleri yazılabilir: $r t=$ $2 \pi$. Bu eşitlikten döngünün (konjonktürün) süresi hesaplanır: $t=2 \pi / r$ dir.

$$
t=\frac{2 \pi}{\sqrt{\left\{\left(\frac{\gamma+\alpha}{\sigma \rho}\right)(\rho[1-(\alpha+\beta) \sigma])\right\}}}=\frac{2 \pi}{\sqrt{(\alpha+\gamma)\left(\frac{1}{\sigma}-(\alpha+\beta)\right.}}
$$

Goodwin konjonktürünün süresi dört parametreye bağlıdır: $(\sigma)$ sermaye hasıla katsayısına, $(\alpha)$ işgücü verimliliğindeki değişmeye, $(\gamma)$ Phillips eğrisinin dikey eksendeki kesim noktasına ve $(\beta)$ nüfus artış hızına bağlıdır.

\section{Türkiye'de Goodwin Dalgasının Süresi (Periyodu)}

(18) nolu denklemdeki $(\sigma)$ sermaye hasıla katsayıs1, $(\alpha)$ işgücü verimliliğindeki değişme, $(\gamma)$ Phillips eğrisinin dikey eksendeki kesim noktası ve $(\beta)$ nüfus artış hızı katsayıları 2000'li yıllarda Türkiye ekonomisi için tahmin edilerek, konjonktür süresi (periyodu) hesaplanabilir. Bu katsayılardan özellikle sermaye hasıla katsayısını $(\sigma)$ tahmin etmek teorik ve pratik açısından ciddi bir zorluktur. Ekonomideki/toplumdaki (özelde de Türkiye ekonomisinde) sermaye stokunu hesaplamayı zorlaştıran en önemli faktör, neyin sermaye olup, neyin olmadı̆̆ının iktisat teorisinde çok karmaşık, çok boyutlu ve çok önemli bir tartışma konusu olmasıdır. Örneğin 
Marx'ta sermaye nesne olarak değil de toplumsal ilişki olarak tanımlanmakta, sermayenin nesne olarak kavramsallaştırılması kabul edilmemektedir (Marx, 2012: 543-560). En azından bu makalede birikim açısından sermayenin nesneleştiği kabul edilerek sermaye stokunun hesaplanabilir olduğu varsayılmaktadır. Bu konu oldukça tartışmalı olsa da sermaye stokunu hesaplayan (özelde de Türkiye için) birçok çalışma bulunmaktadır. Türkiye'de sermaye stokunu hesaplayan çalışmalardan biri de Saygılı ve Cihan'ın (2008) çalışmasıdır. Genelde bu hesaplamada hem makine teçhizat hem de konut stoku, sermaye stoku hesaplamasinda dikkate alınmaktadir. Fakat makine ile konut stokunun birbirini ayrıştırarak yapılan hesaplamalarda Türkiye'deki konjonktür süresini yansıtma derecesi düşük olacaktır. Sermayenin beşeri ve sosyal tarafinı hesaplamak daha da güçtür. Bütün bunlara rağmen Demircioğlu'na göre 2002-2012 y1llar1 arasinda "Türkiye'deki yap1 stoku (konut, işyeri, okul veya hastane yapıları; endüstriyel veya ticari tesislerin binaları; yollar; köprüler vb.) çok yaklaşık değer olarak GSYH'nın bir buçuk katı, makine teçhizat stoku ise yarısı civarında tahmin edilmiştir" (Demircioğlu, 2012: 1-12). Dolayısıyla Demircioğlu'nun hesaplamasının AKP dönemini de kapsadığını dikkate alınarak sermaye hasıla katsayısı Türkiye için $\sigma=2$ olarak tahmin edilmiş veya hesaplanmıştır. Aynı çalışmaya göre eğer sadece makine teçhizatı dikkate alarak sermaye/ hasıla katsayısı ele alınırsa $\sigma=0,5$ olarak hesaplanmaktadır.

Konjonktür süresini hesaplamak için ihtiyaç duyulan diğer bir katsayı da işgücü verimliliğidir $(\alpha)$. İşgücü verimliliği birim işçi başına düşen çıtı miktarıdır. İşücü verimlilik hesaplamalarında işgücü başına düşen üretim (endeksi) ile işçi girdi endeksi orantılanmaktadır. Balkan ve Suiçmez’in (2014) yaptığ1 hesaplara göre 2005-2014 y1lları arasında Türkiye'de işgücü verimliliği yıllık ortalama olarak $\alpha=0,016$ oranında artmaktadır.

(2) nolu denklemdeki Phillips eğrisinin değişim formunda bir denklem olduğu hatırlanırsa, dikey eksene kesim noktası olan $(\gamma)$ değerinin istihdam düzeyinin değişmediği durumlarda ücretlerdeki değişimi gösterdiği söylenebilir. Bundan sonra $(\gamma)$ parametresi için Phillips sabiti isimlendirilmesi kullanılacaktır. Aşağıda 2007-2015 döneminde ücret değişimi ve istihdam verilerinden faydalanarak basit bir regresyon koşulmuş ve $(\gamma)$ değeri tahmin edilmiştir. 'Türkiye'deki ücret verilerindeki eksiklikler dikkate alındığında daha uzun bir veri aralığında regresyon yapılması gerekliliği tartışması da anlamsız bir tartışmadır. 
Tablo 1: Türkiye'de Ücretler ve İstihdam Oranı

\begin{tabular}{|c|c|c|c|}
\hline & Ücret İndeksi & İstihdam Oranı & $\begin{array}{c}\text { Ücret } \\
\text { Değişim Oranı }\end{array}$ \\
\hline 2007 & $\mathbf{7 4 , 2}$ & 40,35 & \\
\hline 2008 & $\mathbf{8 2 , 7}$ & 40,41 & 12,4 \\
\hline 2009 & $\mathbf{9 1 , 1}$ & 39,8 & 7,6 \\
\hline 2010 & $\mathbf{1 0 0 , 0}$ & 41,34 & 9,4 \\
\hline 2011 & $\mathbf{1 0 9 , 3}$ & 43,05 & 11,1 \\
\hline 2012 & $\mathbf{1 2 1 , 9}$ & 43,58 & 10,1 \\
\hline 2013 & $\mathbf{1 3 6 , 9}$ & 43,98 & 13,3 \\
\hline 2014 & $\mathbf{1 5 2 , 5}$ & 45,46 & 10,0 \\
\hline 2015 & $\mathbf{1 7 3 , 0}$ & 46 & 12,0 \\
\hline
\end{tabular}

Kaynak: TUİK ve TCMB.

$\mathrm{Bu}$ çerçevede Ücret De ğtşim $=-\gamma+\rho$ istihdam oran1 olarak tanımlanan Phillips eğrisi tahmini aşağıdaki gibidir:

\section{Ücret Değişimi $=-3,77+0,33$ İstihdam Oranı}

Goodwin konjonktür süresini (periyodunu) hesaplamak için gerekli olan Phillips sabiti $\gamma=\% 3,77$ 'dir. Konjonktür süresini hesaplamak için gerekli olan son parametre $(\beta)$ nüfus artış hızıdır. Türkiye İstatistik Kurumu'na (TÜIK) göre 2010-2015 döneminde Türkiye'deki yıllık nüfus artış oranı $\% 1,3$ 'tür. Bu bilgilerin ışı̆̆ında makine ve teçhizata dayanan sermaye hasıla katsayına göre Goodwin konjonktür dalgasının süresini 2000'li yıllar için hesaplamak için gerekli olan bütün parametreler (19) nolu denklemde bir araya getirilmiştir.

$$
t=\frac{2 \pi}{\sqrt{(\alpha+\gamma)\left(\frac{1}{\sigma}-(\alpha+\beta)\right.}}=\frac{2 \times 3,14}{\sqrt{(0,016+0,037)\left(\frac{1}{0,5}-(0,016+0,013)\right.}}=\frac{6,28}{0,32}=
$$

$19,6 \sim 20 y \square l$

Türkiye ekonomisi için 2000'li ylllarda konjonktür dalgasının süresi 20 yıldır. Bu hesaplamaya göre sermaye stoku makine teçhizat olarak hesaplanırsa, kapitalist karlarda/yatırımlarda ilk on y1llik canlanma (2012 yilına kadar) sürecini diğer bir on ylllk daralma süreci izlemektedir. Goodwin modelindeki (4) nolu denkleme dayanarak kapitalistlerin gelirden 
aldığı payı, yani makro karlılık oranı $\dot{k} / q$ olarak tanımlanabilir: $(\dot{k})$ değişkeni brüt yatırımları (özel ve kamu sektörü makine/teçhizat yatırımlarını kapsamaktadır), (q) da çıktı düzeyini (GSYH) göstermektedir. $\mathrm{Bu}$ verilere göre tanımlanmış, kapitalistlerin gelirden aldıkları paylarla ilgili verilere bakılarak Türkiye için hesaplanan Goodwin konjonktür dalgasının süresi kısmen konfirme edilebilir. Eğer Şekil 2'deki gibi 2001 krizi bir dip nokta kabule edilirse ${ }^{2}$ (ki Türk Cumhuriyet tarihinin en büyük krizi olarak kayda geçti), 20 yıllık Goodwin konjonktür dalgasının canlanma süresi 2001'den başlayıp 2011 yllına kadar devam edecektir (Şekil 2'deki düz mavi çizgi). Gerçekten sanayi sektöründeki katma değer artışları Türkiye sanayisi için incelendiğinde 2002-2010 yılları arasında \%190 ki bu sanayide karların arttığının bir göstergesidir (Terzioğlu\&Dişbudak, 2012). Modelin karlılık oranı ile ilgili konjonktür öngörüsü fili karlılık oranı tarafından da desteklenmektedir. Baklavalı mavi çizgi ile kesikli mavi çizgi birbiri ile uyumludur. Ancak doğrulanması zor olan, konjonktürün diğer kalan yarıs1 yani 2012-2022 arasındaki yllarda yatırım/karların GSYH oranının daralma yaşanıp yaşanmayacağı veya kapitalistlerin gelirden aldıkları payın azalıp azalmayacağının kısacası kar oranlarının düşüp düşmeyeceğinin doğrulanmasıdır. Modelin bu çıkarımını sadece zaman test edebilir.

Goodwin modeline dayanarak Türkiye ekonomisi için hesaplanan konjonktür süresinin bir eksikliği de hesaplamanın sadece makine/teçhizat yatırımlarına göre tanımlanan sermaye stokuna bağlı olmasıdır. Türkiye ekonomisindeki gayrimenkul sektörünün ağıllı̆̆ını dikkate alarak sermaye hasıla katsayısı dikkate alınmalıdır. Demircioğlu'nun hesaplarına göre gayrimenkulü de dikkate alarak hesaplanan sermaye hasıla katsayısı 2'dir. Doğal olarak yeni hesaplamaya göre Goodwin konjonktür dalgasının süresi değişecektir³.

\section{$39 y \square l$}

$$
t=\frac{2 \pi}{\sqrt{(\alpha+\gamma)\left(\frac{1}{\sigma}-(\alpha+\beta)\right.}}=\frac{2 \times 3,14}{\sqrt{(0,016+0,037)\left(\frac{1}{2}-(0,016+0,013)\right.}}=\frac{6,28}{0,16}=39,25 \cong
$$

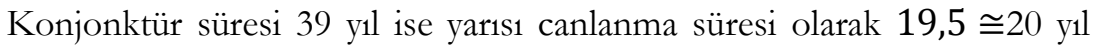
hesaplanabilir (Şekil 2'deki kesikli ve kırmızı çizgi). Dolayısıyla 2001 yılı kriz ve dolayisıyla dip kabul edilirse 2021'e kadar süren bir canlanma

\footnotetext{
2،'Türkiye'nin değişimindeki en önemli dönüm noktalarından birisi de 2001 yllında yaşanan büyük ekonomik krizdir. Türkiye, 2001 krizi sonucunda GSYH'sının dörtte birini kaybetti. On binlerce insan işsiz kaldı, 2000 yllında yüzde 6,5 olan işsizlik oranı 2002'de yüzde 10,3’e tırmandı, işini kaybetmeyenlerin geliri düştü, ücretleri azalanlar, işlerini de kaybetmemek için seslerini çıkaramadı, pek çok insan bankalara olan kredi borçlarını ödeyemedi, binlerce işyeri kapandı, insanlar korktular, sindiler, aç kaldılar. Ve sonuçta fedakârlıklara razı hale geldiler" (Eğilmez, 2016).

${ }^{3}$ Goodwin dalgalarındaki değişimin nedenleri için bkz. Stockhammer and Michell (2014).
} 
bekleyebiliriz. Yaklaşık 40 yıllık bir dalga büyüklügü iktisadi açıdan uzun bir dalgadır. Bu noktada farklı sermaye birikim düzeylerine bağlı olarak farklı dalga sürelerinin ortaya çıkması Kondratieff'in uzun dönem dalga kavramını da hatırlatmaktadır. Kondratieff, kapitalizm ortalama 50 ylllık uzun dönem dalgalarının bulunduğunu ve bu dalgaların teknoloji, savaş, yeni pazar ve parasal dönüşüm gibi faktörlerce bağlansa bile bu gelişmelerin de kapitalizme içsel olduğunu iddia etmektedir (Kondratieff, 1926)4.

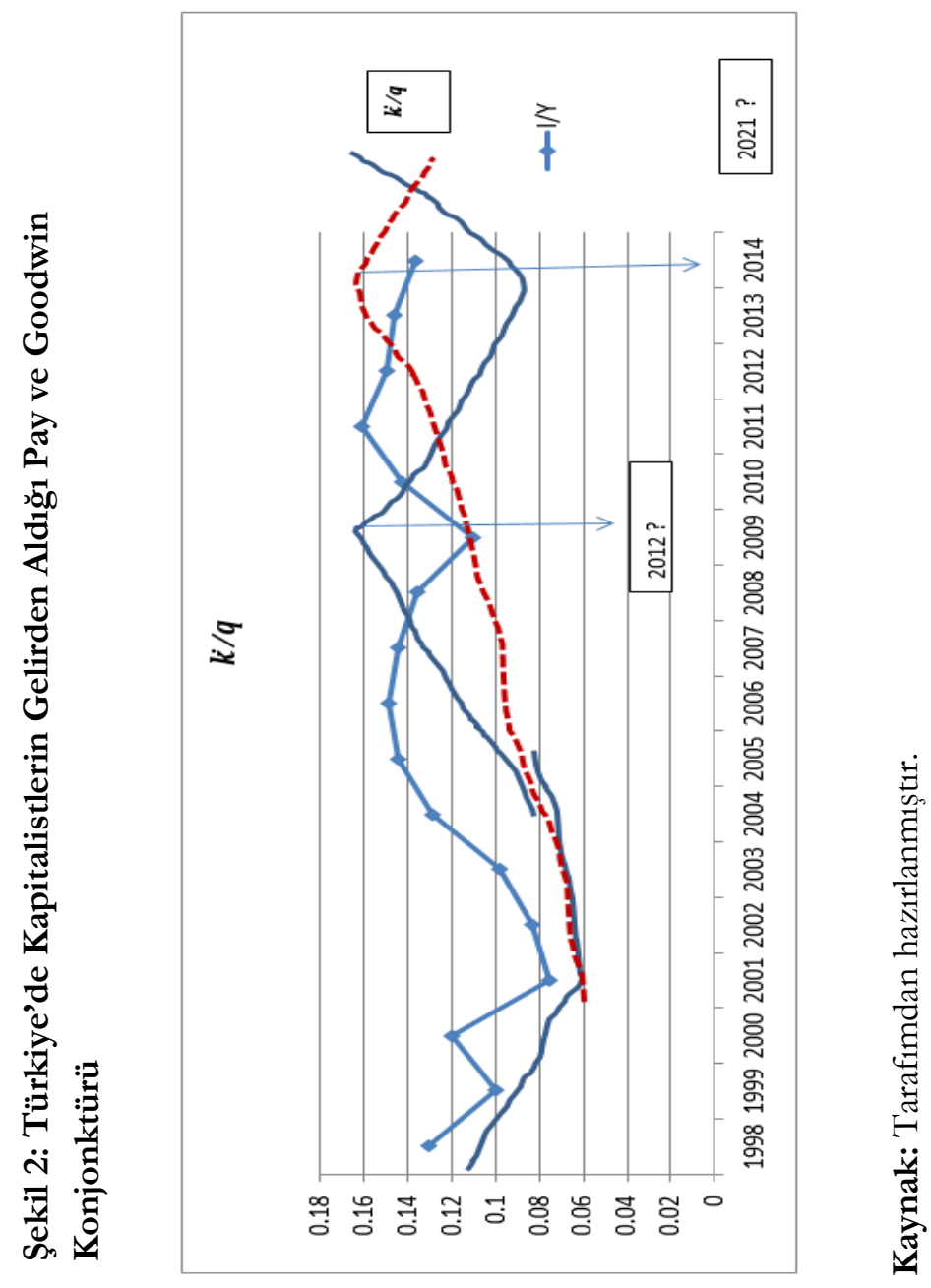

\footnotetext{
${ }^{4}$ Ekonomik dalgalanmaların \%7' ini dişsal teknolojik şoklara bağlayan görüşlerde bulunmaktadır. Bakınız Finn Kayland, Edward Prescott, (1991), "Hours and Employment Variation in Business Cycle Theory", Economic Theory, 1: 63-81.
} 
Farklı sermaye hasıla katsayısı veya farklı sermaye biçimleri için konjonktür süresi değişmektedir. İktisat teorisi açısından firavunların neden piramit yaptıkları ortaya çıkmaktadır. Toplumdaki sermaye stoku büyüdükçe konjonktür süresi uzamaktadır (Keynes, 1936). İktisat teorisi açısından ilgi çekici olan bu sonuç politik iktisat açısından, özellikle Türk siyasal hayatı için daha da ilginçtir. "Hiçbir konu tek bir değişkene indirgenebilecek kadar basit değildir. Ama 2001 krizinin yarattığ1 sonuçlar AKP’ye iktidar yollarını açan en önemli değişkenlerden birisi gibi görünmektedir. Bu iddiamı seçimlerden sonra yapılan anketlerin sonuçları da doğrulamaktadır. Çünkü insanlar AKP'ye oy verme nedenleri arasında en çok ekonomik nedenleri işaretlemişlerdir... Bunun yanında... 2001 krizinin bir başka önemli ekonomik etkisi de Türkiye’nin büyüme modelini değiştirmesidir ${ }^{5}$. Türkiye, bu krize kadar bütçe açı̆̆1 veren, kamu kesimini borçlandıran bir büyüme modeli uyguluyordu. Krizden sonra, iktidarın AKP'ye geçmesiyle birlikte Türkiye, bütçe açı̆̆1 yerine cari açık veren, kamu kesimi yerine özel kesimi borçlandıran yeni büyüme modeline geçiş yaptı" (Ĕgilmez, 2016). Dünyadaki likidite bolluğu da şirketlerin yurtdışından borçlanma imkanını arttırdı. Bu sürede Türkiye'nin sermaye stoku hem makine teçhizat hem de gayrimenkul stoku olarak büyüdü. Özellikle 2005 yllından itibaren reel faizlerin düşmesi ile beraber konut piyasası Türkiye'de hızlı bir şekilde gelişim göstermiştir (Büyükduman, 2012: 143-157). Dolayısıyla Türkiye'de sermaye stokunun bileşenlerinden gayrimenkul sektörü dikkate alındığında konjonktürün süresi 39 yıla, canlanma açısından da süre yaklaşık 20 yıla çıkmaktadır. Türkiye'de konjonktürün yönü 2021'lere kadar yukarı yönlü olabilir. Eğer seçmenler için ekonominin önemli bir karar değişkeni olduğu ve modelin konjonktür süresinin doğru olduğu kabul edilirse, iktisatçıların (analizcilerin) sürekli kriz beklentisi veya birkaç yıllık makro ekonomik verilere bakarak iktidarın ekonomik olarak zayıfladığı dolayısıyla AKP'nin oy ve güç kaybetmesi ile ilgili beklentiler geliştirmeleri hatalı olabilir.

\section{Sonuç}

Bu makaledeki Goodwin konjonktür analizinden iki sonuç çıkmaktadır. Birincisi siyasi partilerin girdikleri seçimlerde gösterdikleri performansı değerlendirmek için birkaç ylllı büyüme verileri yerine, konjonktüre bir bütün olarak bakılmalıdır. 2001'de başlayan canlanma süreci 2021 yılına kadar devam ediyorsa, AKP'nin seçimlerden aldığı oylar da hesaplanan konjonktür süresiyle uyumludur. Modele göre yatırımların GSYH'ya oranı artmaya devam edecektir. Seçim sonuçlarına bakıldığında AKP 2002 seçimlerinde \%34,8, 2007 seçimlerinde \%46,5, 2011 seçimlerinde \%49,3,

\footnotetext{
${ }^{5}$ Süslü ve Balmumcu’ya göre Türkiye ekonomisinde uzun vadeli büyüme stratejisi yerine kısa vadeli enflasyon açığı stratejisi izlenmesi, özel sektörün ekonomideki verimliğini azaltmış, borçlanarak büyümeye neden olmuştur. Bu durum da kamu kesimi bütçe dengesini sağlarken özel kesimin tasarruf açığı yapmasına neden olmuştur (Süslü ve Balmumcu, 2015).
} 
2015 seçimlerinde $\% 40,8$ oy alırken hemen ertesi aylarda yapılan seçimlerde de \%49,2 oy almıştır. Konjonktürün yönü 2021 yllına kadar canlanma şeklinde devam ederse önümüzdeki seçimler de (2019 Genel Seçimleri) de bu oy oranının ekonomik nedenlerle değişeceğini beklemek gerçekçi olmayacaktır. Doğal olarak Goodwin modelinde konjonktürü belirleyen parametreler değiştiğinde (bu değişmelerin içsel ve dişsal olup olmadığını tartışmıyoruz) süre değişecektir. Örneğin Suriye kaynaklı göç ve nüfus artış hızının değişmesi, Türkiye ekonomisi için hayati olduğunu düşündüğümüz gayrimenkul piyasası ve bunun sermaye içindeki ağırlığı gibi faktörlerde meydana gelecek değişmeler, siyasal şoklar, düzenlemeler vb. gelişmelerin sadece konjonktürün süresini değil iktidarı da etkileyeceği söylenebilir. Ancak bu değişikleri öngörebilmek mümkün değildir. Özellikle küresel ekonomiye ve siyasal süreçlere entegre olmuş Türkiye ekonomisi ve sermaye birikim süreci daha karışık bir hal almıstır ${ }^{6}$. Dünyadaki likidite/sermaye bolluğu, küresel siyasal ve ekonomik rekabet farklı birikim büyüklüklerine ve konjonktür sürelerine neden olabilir.

İkinci olarak bir ekonomide farklı konjonktür sürelerini belirleyen farklı sermaye biçim türleri/büyüklükleri vardır. Sermaye stoku büyüdükçe konjonktür süresi uzamaktadır. Türkiye için makine/teçhizata dayalı sermaye hasıla katsayıs1 20 ylllı bir konjonktür süresine neden olurken, makine/teçhizat + gayrimenkul bileşiminden meydana gelen sermaye hasila katsayısı süreyi 39,4 yıla çıkarmaktadır. Farklı sektörlerin farklı sermaye hasıla katsayıları, farklı konjonktür süreleri veya fazları yaratabilir. Bu farklı sektör fazları birbirini desteleyerek ekonomik canlanmayı uzatabileceği gibi birbirini nötrleyerek ekonomik canlanmayı kısaltabilir. Dolayısıyla AKP dönemini ekonomi politik açıdan anlamak ve değerlendirmek isteyen iktisatçllar ve sosyal bilimciler, birkaç sektör ve birkaç yıllık makro veri yerine, birçok sektörü gözlemlemek, bir araya getirmek özellikle toplam sermayenin büyüklüğünü doğru bir şekilde hesaplamak/tahmin etmek zorunda olduklarını görmeleri gerekmektedir.

\footnotetext{
${ }^{6}$ Uzun dönem dalgalanmalar ve küresel gelişmeler için bkz Richard Rosecrance, (1987), Long Cycle Theory and International Relations”, Internationel Organization, MIT Press, Vol:41, No:2, pp.283-301.
} 


\section{Kaynakça}

Balkan, D., Suiçmez, H. (2015) Türkiye ve Dünya'da İşgücü Verimliliğinin Karşılaştırmalı Analizi, Mülkiye İktisadi ve Sosyal Araștırmalar Merkezi Raporu, No:13.

Büyükduman, A. (2012) Konut Balonu, Scala Yayıncllı, İstanbul.

Demircioğlu, U. (2012) Türkiye'de Sermaye Stoku ve Sermaye Hizmetleri Endeksi, TCMB Ekonomi Notlar, Say1: 2012-26, ss. 1-12.

Desai, M. (2011) Marx’in İntikamı, Çev. G. Özgür, Efil Yayınları, Ankara.

Desai, M., Brian, H., Mosley, A., Pemberton, M. (2003) On An Inconsistency In The Goodwin Model Of The Growth Cycle, https://www.researchgate.net/publication/242077116 On an In consistency in the GoodwinModel of the Growth Cycle, ss. 114, (Erişim Tarihi: 29.09.2016).

Eğilmez, M. (2016) Türkiye'deki Değişimin Sosyo-ekonomik Analizi, http://www.mahfiegilmez.com/2014/03/turkiyedeki-degisiminsosyo-ekonomik.html, (Erişim Tarihi: 15.09.2016).

Goodwin, R. M. (1965) A Growth Cycle, http://orion.math.iastate.edu/driessel/14Models/1967growth.pdf, (Erişim Tarihi: 15.06.2016).

Harvie, D. (2000) Testing Goodwin: Growth Cycles In Ten OECD Countries, Cambridge Journal of Economics, 24, pp. 349-376.

Kayland F., Prescott, E. (1991) Hours and Employment Variation in Business Cycle Theory, Economic Theory, 1:63-81.

Keynes, J. M. (1936) Istihdam, Faiz, ve Para Genel Teorisi, Çev. A. Baltacigil, Minnetoğlu.

Kondratieff, N. D. (2010) İktisadi Yaşamm Uzun Dalgalar Irvig Fischer ve Jonh M. Keynes Üzerine, Çev. U. S. Akalın, Kalkedon Yayınları, İstanbul.

Marx, K. (2012) Kapital II, Çev. M. Selik ve N. Satılgan, Yordam Kitap, İstanbul.

Rosecrance, R. (1987) Long Cycle Theory and International Relations, Internationel Organization, MIT Press, Vol.41, No: 2, pp. 283-301.

Saygıll, Ş., Cihan, C. (2008) Türkiye Ekonomisinin Büyüme Dinamikleri: 1987-2007 Döneminde Büyümenin Kaynakları, Temel Sorunlar ve Potansiyel Büyüme Oranı, TÜSİAD ve TCMB. 
Stockhammer, E., Michell, J. (2014) Pseudo-Goodwin Cycles In A Minsky Model, Post Keynesian Economics Study Group Working Paper, No: 1405.

Süslü, B., Balmumcu, Ö. (2015) Türkiye Ekonomisi İçin Tasarruf Açığ1 ve Para Politikası, Uluslararası Yönetim İktisat Ve İsletme Dergisi, 11(25), ss. 1-15.

Terzioğlu, M., Dişbudak, C. (2012) Krizlerin Türkiye Sanayi Sektörüne Etkilerinin Analizi: Sektörel Pay Yaklaşımı, http://teacongress.org/papers2012/TERZIOGLUDISBUDAK.pdf., (Erişim Tarihi: 25.06.2016).

Weber, L. (2005) A Contribution To Goodwin's Growth Cycle Model From A System Dynamics Perspective, http://www.systemdynamics.org/ conferences/2005/proceed / papers/ WEBER196.pdf.,pp. 1-28,_(Erişim Tarihi: 15.07.2016). 